\title{
Development and manufacturing of SPO X-ray mirrors
}

Landgraf, Boris; Collon, Maximilien J.; Vacanti, Giuseppe; Barriére, Nicolas M.; Günther, Ramses; Vervest, Mark; Voruz, Luc; Verhoeckx, Sjoerd; Babic, Ljubisa; Keek, Laurens

Total number of authors:

35

Published in:

Optics for EUV, X-Ray, and Gamma-Ray Astronomy IX

Link to article, DOI:

$10.1117 / 12.2530941$

Publication date:

2019

Document Version

Publisher's PDF, also known as Version of record

Link back to DTU Orbit

Citation (APA):

Landgraf, B., Collon, M. J., Vacanti, G., Barriére, N. M., Günther, R., Vervest, M., Voruz, L., Verhoeckx, S., Babic, L., Keek, L., Girou, D., Okma, B., Beijersbergen, M. W., Bavdaz, M., Wille, E., Fransen, S., Shortt, B., Ferreira, I., Haneveld, J., ... Ball, K. (2019). Development and manufacturing of SPO X-ray mirrors. In S. L. OD., \& G. P. (Eds.), Optics for EUV, X-Ray, and Gamma-Ray Astronomy IX (Vol. 11119). [111190E] SPIE International Society for Optical Engineering. Proceedings of SPIE - The International Society for Optical Engineering https://doi.org/10.1117/12.2530941

\section{General rights}

Copyright and moral rights for the publications made accessible in the public portal are retained by the authors and/or other copyright owners and it is a condition of accessing publications that users recognise and abide by the legal requirements associated with these rights.

- Users may download and print one copy of any publication from the public portal for the purpose of private study or research.

- You may not further distribute the material or use it for any profit-making activity or commercial gain

- You may freely distribute the URL identifying the publication in the public portal 


\section{Development and manufacturing of SPO X-ray mirrors}

Boris Landgraf, Maximilien J. Collon, Giuseppe Vacanti, Nicolas M. Barrière, Ramses Günther, et al.

Boris Landgraf, Maximilien J. Collon, Giuseppe Vacanti, Nicolas M. Barrière,

Ramses Günther, Mark Vervest, Luc Voruz, Sjoerd Verhoeckx, Ljubiša Babić, Laurens Keek, David Girou, Ben Okma, Marco W. Beijersbergen, Marcos Bavdaz, Eric Wille, Sebastiaan Fransen, Brian Shortt, Ivo Ferreira, Jeroen Haneveld, Arenda Koelewijn, Ronald Start, Maurice Wijnperlé, Jan-Joost Lankwarden, Coen van Baren, Paul Hieltjes, Jan Willem den Herder, Vadim Burwitz, Giovanni Pareschi, Sonny Massahi, Desirée Della Monica Ferreira, Finn E. Christensen, Giuseppe Valsecchi, Paul Oliver, Ian Chequer, Kevin Ball, "Development and manufacturing of SPO X-ray mirrors," Proc. SPIE 11119, Optics for EUV, X-Ray, and Gamma-Ray Astronomy IX, 111190E (30 October 2019); doi: 10.1117/12.2530941

GPIE Event: SPIE Optical Engineering + Applications, 2019, San Diego, California, United States 


\title{
Development and manufacturing of SPO X-ray mirrors
}

Boris Landgraf*a, Maximilien J. Collon ${ }^{\mathrm{a}}$, Giuseppe Vacanti ${ }^{\mathrm{a}}$, Nicolas M. Barrière ${ }^{\mathrm{a}}$, Ramses Günther $^{\mathrm{a}}$, Mark Vervest ${ }^{\mathrm{a}}$, Luc Voruz ${ }^{\mathrm{a}}$, Sjoerd Verhoeckx ${ }^{\mathrm{a}}$, Ljubiša Babića ${ }^{\mathrm{a}}$, Laurens Keek ${ }^{\mathrm{a}}$, David Girou $^{\mathrm{a}}$, Ben Okma ${ }^{\mathrm{a}}$, Marco W. Beijersbergen ${ }^{\mathrm{a}}$, Marcos Bavdaz ${ }^{\mathrm{b}}$, Eric Wille ${ }^{\mathrm{b}}$, Sebastiaan Fransen ${ }^{\mathrm{b}}$,

Brian Shortt $^{\mathrm{b}}$, Ivo Ferreira ${ }^{\mathrm{b}}$, Jeroen Haneveld ${ }^{\mathrm{c}}$, Arenda Koelewijn ${ }^{\mathrm{c}}$, Ronald Start ${ }^{\mathrm{c}}$, Maurice Wijnperléc $^{c}$ Jan-Joost Lankwarden ${ }^{c}$, Coen van Baren ${ }^{d}$, Paul Hieltjes ${ }^{d}$, Jan Willem den Herder ${ }^{d}$, Vadim Burwitz $^{\mathrm{e}}$, Giovanni Pareschi ${ }^{\mathrm{f}}$, Sonny Massahi ${ }^{\mathrm{g}}$, Desirée Della Monica Ferreira ${ }^{\mathrm{g}}$, Finn E. Christensen ${ }^{\mathrm{g}}$, Giuseppe Valsecchi ${ }^{\mathrm{h}}$, Paul Oliver ${ }^{\mathrm{i}}$, Ian Chequer ${ }^{\mathrm{i}}$, Kevin Ball ${ }^{\mathrm{i}}$

${ }^{\text {a }}$ cosine, Oosteinde 36, $2361 \mathrm{HE}$ Warmond, The Netherlands

${ }^{\mathrm{b}}$ European Space Agency, ESTEC, Keplerlaan 1, PO Box 299, 2200 AG Noordwijk, The Netherlands

${ }^{\mathrm{c}}$ Micronit Microfluidics B.V., Colosseum 15, 7521 PV Enschede, The Netherlands

${ }^{\mathrm{d}}$ SRON, Sorbonnelaan 2, 3584 CA Utrecht, The Netherlands

${ }^{\mathrm{e}}$ MPI f. extraterrestrische Physik, Giessenbachstrasse 1, 85748 Garching, Germany

${ }^{\mathrm{f}}$ INAF Osservatorio Astronomico di Brera, Via E. Bianchi 46 I- 23807, Merate (Lc), Italy

${ }^{g}$ DTU Space, Technical University of Denmark, Building 327, DK - 2800 Kgs. Lyngby, Denmark

${ }^{\mathrm{h}}$ Media Lario S.r.1., Località Pascolo, 23842 Bosisio Parini(LC), Italy

${ }^{\mathrm{i}}$ Teledyne e2v (UK) Ltd., 106 Waterhouse Lane, Chelmsford, Essex CM1 2QU, England

\begin{abstract}
The Silicon Pore Optics (SPO) technology has been established as a new type of X-ray optics enabling future X-ray observatories such as Athena and Arcus. SPO is being developed at cosine together with the European Space Agency (ESA) and academic as well as industrial partners. The SPO modules are lightweight, yet stiff, high-resolution X-ray optics, allowing missions to reach a large effective area of several square meters. These properties of the optics are mainly linked to the mirror plates consisting of mono-crystalline silicon. Silicon is rigid, has a relatively low density, a very good thermal conductivity and excellent surface finish, both in terms of figure and surface roughness. For Athena, a large number of mirror plates is required, around 150,000 for the goal configuration. With the technology spin-in from the semiconductor industry, mass production processes can be employed to manufacture rectangular shapes SPO mirror plates in high quality, large quantity and at low cost. Within the last years, several aspects of the SPO mirror plate have been reviewed and undergone further developments in terms of effective area, intrinsic behavior of the mirror plates and mass production capability. In view of flight model production, a second source of mirror plates has been added in addition to the first plate supplier. The paper will provide an overview of most recent plate design, metrology and production developments.
\end{abstract}

Keywords: X-ray optics, X-ray astronomy, silicon, wafer, stack, pore optics, X-ray telescopes, ATHENA, ARCUS, SPO

*b.landgraf@cosine.nl; www.cosine.nl, www.highenergyoptics.com

\section{INTRODUCTION}

This report details the process steps utilized in the manufacture of silicon mirror plates for SPO [10, 12-18]. The plate manufacturing process begins with double-sided polished $300 \mathrm{~mm}$ wafers, and ends with diced, ribbed, wedged, and coated SPO plates which can be subsequently stacked to form an optical unit $[1,2]$. SPO are currently fabricated using a combination of established semiconductor fabrication techniques and novel fabrication techniques specifically developed for ESA's Athena mission. The scientific community has specified a HEW optical resolution of five arc-seconds, and an

Optics for EUV, X-Ray, and Gamma-Ray Astronomy IX, edited by Stephen L. O'Dell, Giovanni Pareschi, Proc. of SPIE Vol. 11119, 111190E · C 2019 SPIE · CCC code: 0277-786X/19/\$21 · doi: 10.1117/12.2530941 
energy-dependent effective area of up to $1.5 \mathrm{~m}^{2}$ [3-6]. All research and development effort to date has focused on achieving these goals and eliminating the most significant sources of error.

Silicon pore optics are being developed by a consortium of industrial partners which is coordinated by cosine Research B.V. and led by ESA. In 2007, Micronit Microtechnologies B.V. joined the consortium and assumed responsibility for the technology development of manufacturing silicon mirror plates for Athena. In 2016, Athena's second supplier Teledyne imaging joined the consortium and started to develop the process to manufacture SPO plates. Until now, numerous process innovations have significantly improved the quality of SPO plates and also reduced manufacturing cost.

In Figure Figure 1, the process flow towards production of SPO plates is depicted. The production of SPO plates consists of dicing $300 \mathrm{~mm}$ wafers into square shaped plates, ribbing the plates to create grooves along the optical axis, wedging the plates to create a thickness taper along the optical axis, and coating to provide a patterned metallic layer on the reflective surfaces of the plates.

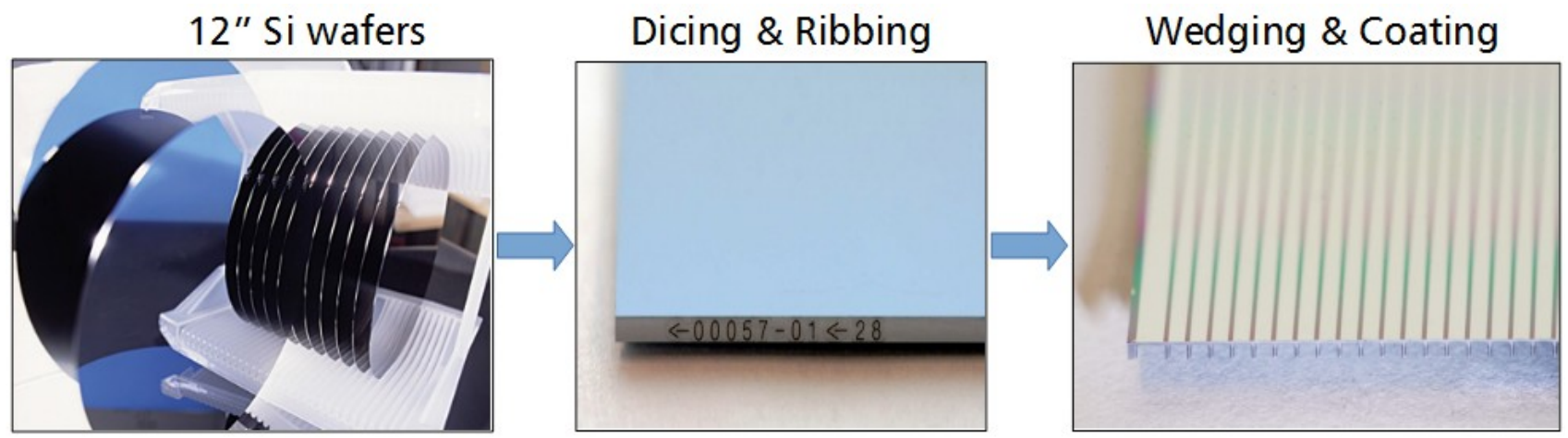

Figure 1. Overview of process flow for production of SPO mirror plates.

\section{SILICON MIRROR PLATE PROCESS FLOW}

\section{Wafer dicing and plate ribbing}

As shown in Figure 1, the production of SPO plates starts with dicing double-sided polished $300 \mathrm{~mm}$ monocrystalline silicon wafers, which have specifications of $1 \AA$ RMS surface roughness and a total thickness variation (TTV) of less than $0.2 \mu \mathrm{m}$, into square shaped plates of dimensions $40 \times 120 \mathrm{~mm}^{2}$ to $100 \times 20 \mathrm{~mm}^{2}$.
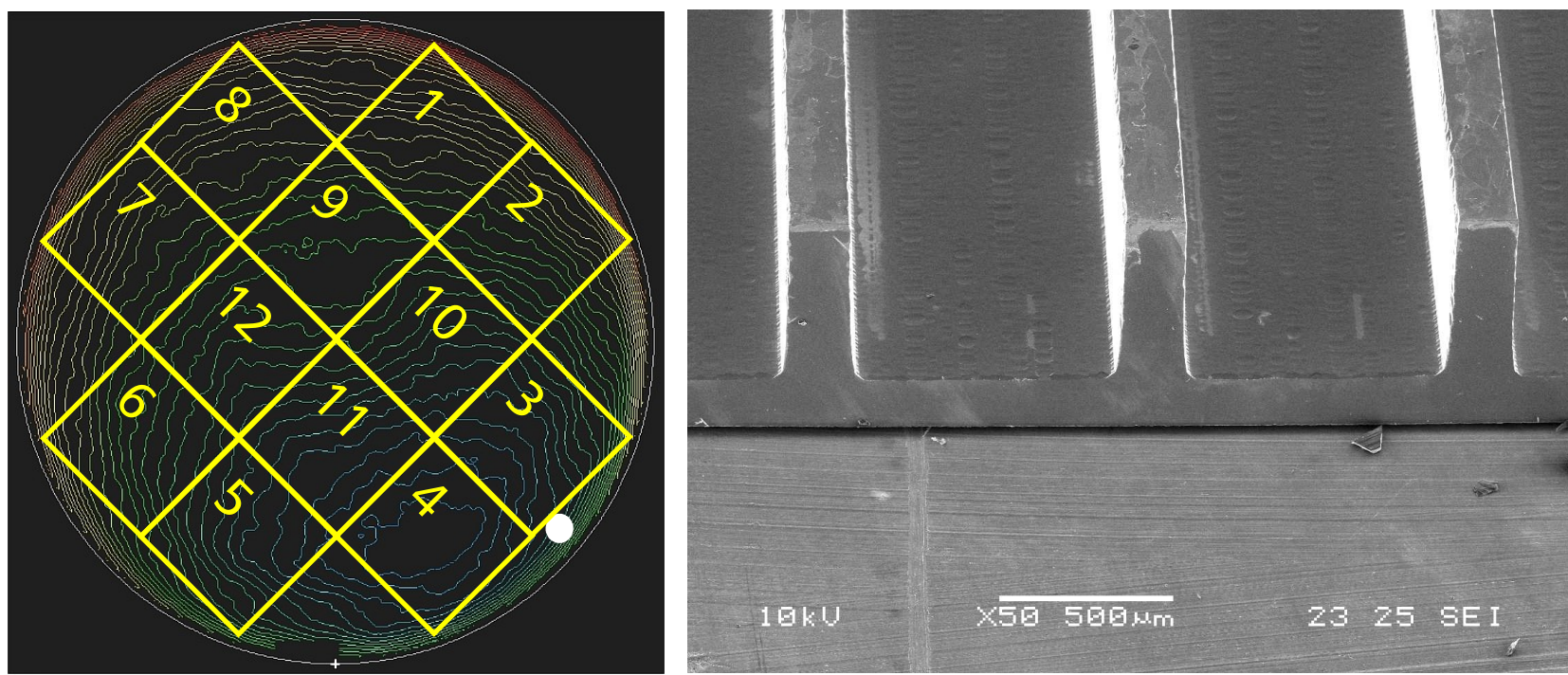

Figure 2. Dicing and ribbing of double-sided polished $300 \mathrm{~mm}$ monocsytalline silicon wafer into SPO plates. 
The left image in Figure 2 shows the mirror dicing plate map on the $300 \mathrm{~mm}$ wafer. The orientation of plate edges is aligned with a silicon crystal plane to ensure correct etching behavior in subsequent chemical processing steps.

During the ribbing process of SPO mirror plates, grooves are diced in the silicon substrate to create pores for X-ray optics. A scanning electron microscope image of a plate with grooves is shown in the right image in Figure 2. The rib pitch, rib width and membrane thickness are variable in the order of $1 \mathrm{~mm}$ to $3 \mathrm{~mm}, 0.17 \mathrm{~mm}$ and $0.15 \mathrm{~mm}$, respectively. The grooves form the empty space for X-rays to enter and be reflected off a mirror, whereas the ribs provide the required structural stiffness to the optical units. Since the mirror plates will be curved in the stacking process to the radius of the telescope lens, the plates need to be as thin as possible. The plate membrane thickness thereby determines the flexibility of the plates and the ribs provide the individual mirrors with the appropriate distance. The top side of these ribs will be bonded to the mirror surface of another SPO mirror plate and stacked to a height of up to 35 plates.

\section{Wedging and coating}

As a next step in SPO plate production, a wedge angle of 3.3 arc-seconds, with an accuracy of one to two percent, is processed into the plates in rib direction. This wedging of diced and ribbed plates is done wet-chemically. The goal of the wedging process is to taper plates along the optical axis to create a conical approximation to a Wolter I Optic [4]. Without wedging, a stack of plates would form a cylindrical approximation to a Wolter I optic when SPO plates are stacked subsequently. The picture of the reflective side of a wedged middle radius SPO plate is shown in the left image in Figure 3. The different colors are due to the thickness variations in the wedge.

After wedging, a final processing step is necessary to boost the reflectivity of the SPO mirror plates. Metal coatings such as iridium and low- $\mathrm{Z}$ overcoatings such as $\mathrm{SiC}$ or $\mathrm{B}_{4} \mathrm{C}$ are currently under investigation as materials for obtaining the required X-ray reflectivity for Athena [16,17]. Patterning of the metal layer is needed to ensure bondability of the silicon mirror plates during the stacking process. Standard photolithographic techniques as applied in semiconductor industry are used to protect the bonding area of the mirror plates against metal deposition. After metal layer deposition, the excess metal, which is coated in the bonding areas, can be removed easily by a lift-off process. The edge definition of the resulting patterned coating is accurate to a micrometer. A patterned coated middle radius SPO plate is shown in Figure Figure 3. Further development to optimize the photoresist coating process and to prepare the process for mass production is ongoing.


Figure 3. (Left) Wedged middle radius SPO plate. (Right) Patterned coated middle radius SPO plate.

\section{NEW SPO PLATE TYPES WITH WIDER PORES TOWARDS MORE EFFECTIVE AREA}

Until spring 2019, most of the development work has been done with three plates types of inner (250 mm radius of curvature), middle ( $737 \mathrm{~mm}$ radius of curvature) and outer radius (1500 $\mathrm{mm}$ radius of curvature). These are shown in 
Figure Figure 4. Recently, we have started to test SPO plates with wider pores and thinner membrane thickness to increase the effective area while keeping the impact on the HEW of the optics minimal. First promising experiments have been performed with middle and outer radius SPO plates shown in the left and right pictures in Figure 5, respectively. Here, the effective area has been increased by widening the pores by a factor of 2.46 and 2.00, respectively. The investigations on varying pore width and height and the impact on the performance of the optics are ongoing.
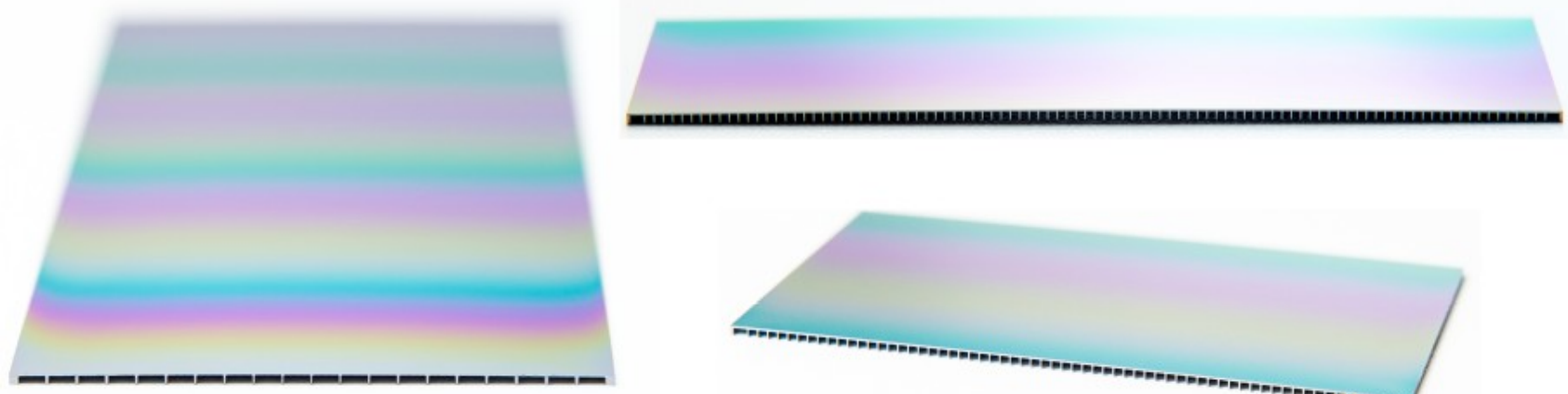

Figure 4. Pictures of inner, middle and outer radius SPO plates.
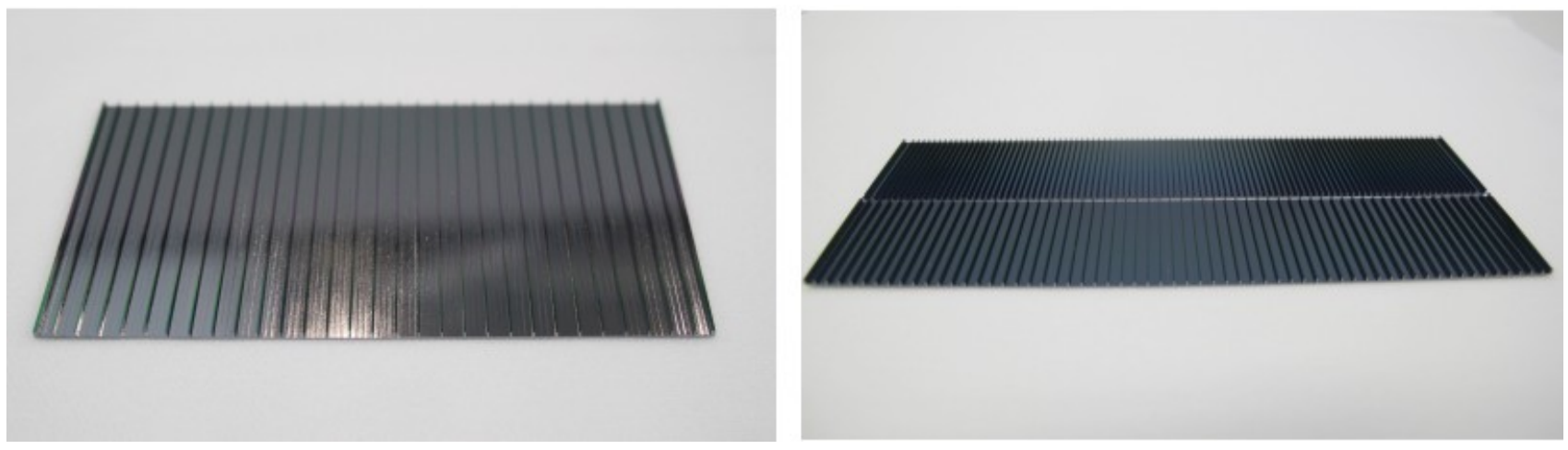

Figure 5. (Left) Middle radius SPO plate with wider pores. (Right) The top outer radius plate has the current default pore width and the bottom one the wider pore width.

\section{PROCESS IMPROVEMENTS FOR BETTER PERFORMANCE}

As a latest development, a total thickness variation (TTV) measurement system has been procured, installed and further developed at cosine to not only measure the wedge of SPO plates on the reflective and ribbed side but also to measure the TTV of an entire $0.8 \mathrm{~mm}$-thick SPO plate to an accuracy of a few nanometers. A picture of the system is shown in the left image in Figure 6.

With the new TTV measurement system, a substantial effort has been made to better understand and improve the quality of the wedge of SPO plates. We recognized two main issues: a systematic bias in the wedge angle, and systematic shape deviations in the wedge layers that contribute to the stack-up error.

At the moment, the two plate suppliers are only able to measure the reflective side of SPO plates to check the conformance of the wedge angle to the nominal value. This is due to limitations of their metrology systems. The cosine TTV measurements on both sides of plates reveal, however, that the wedge angle is not identical on the ribbed and reflective sides. We find that the total wedge angle is systematically larger than the nominal value as for several middle radius SPO plates. This is shown in the right graph in Figure 6. For the plate production process in June 2019, an offset 
of $0.086 \pm 0.002$ arc-seconds was found. Ray trace simulations establish that this wedge offset causes an increase of HEW of about 2.5" for a 34-plate X-ray Optical Unit (XOU).

Based on the results of the new metrology systems, the plate suppliers are now adjusting their wedging process to account for this offset.
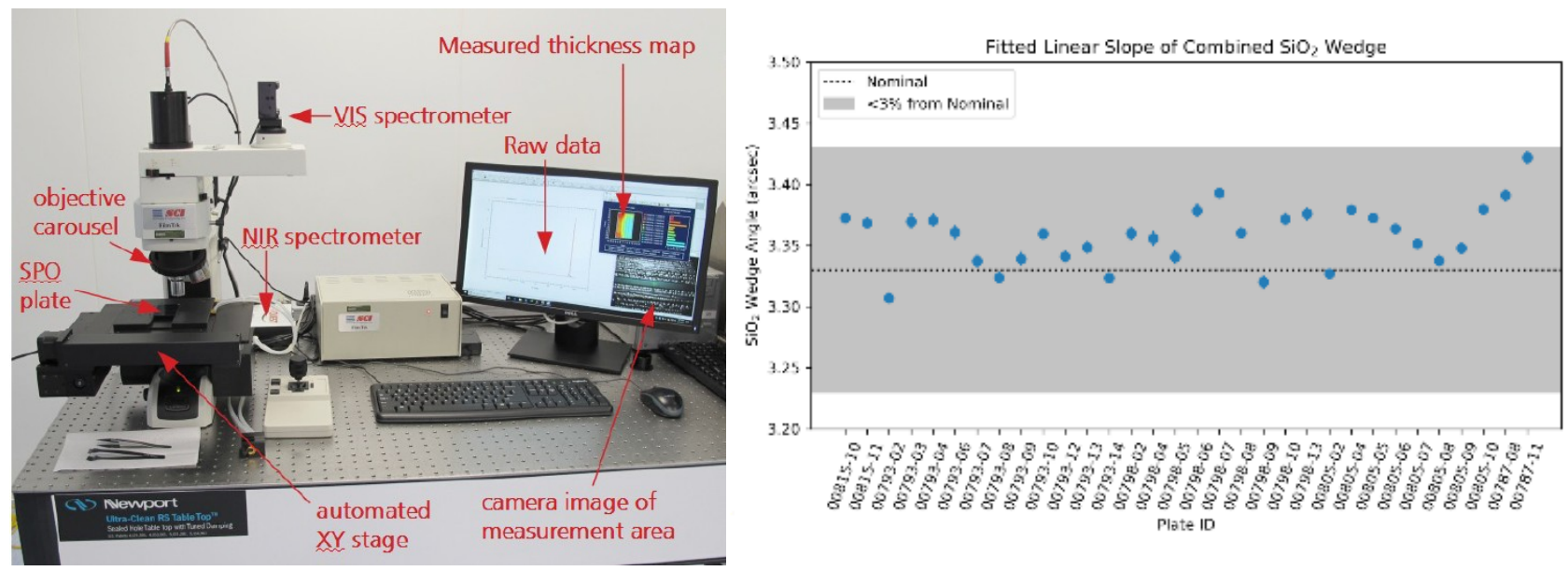

Figure 6. (Left) TTV measurement system at cosine. (Right) Wedge angle versus SPO plate number.

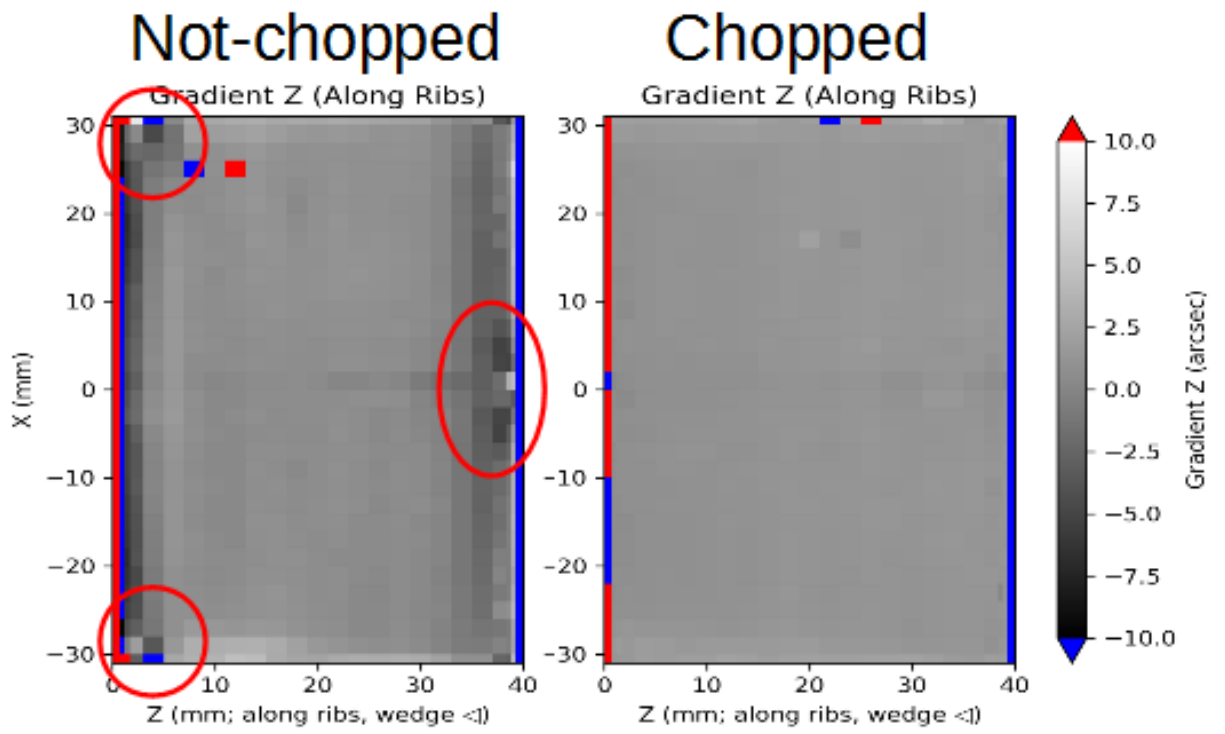

Figure 7. Axial slope deviation predicted from summing the wedge TTV profiles of 20 (left) non-chopped and (right) chopped SPO plates. The non-chopped plates show substantial slope deviations at the plate edges, which are removed when the plates are chopped (right image). Note that the red/blue seen at the very ends of the ribs are due to measurement artifacts at the edges. 
We have also discovered that the wedging process introduces defects along the edges of SPO plates. This has been observed in height maps of the wedge acquired by cosine's TTV system. The impact of those features on stack quality will increase by stack-up. The left image in Figure 7 shows a map of summed up TTV profiles of a series of so-called "non-chopped" middle radius SPO plates. A map of the residual axial slope errors has been created to make it comparable to the ones generated by our in-house stacking metrology Fringe Reflection Technique (FRT). Substantial deviations from the nominal shape are clearly visibe along the edges as well as the local defects highlighted by red circles.

As a solution to these shape deviations, larger middle radius SPO plates in rib direction are getting produced. After wedging, the mirror plates are getting shortened to the nominal length. With this process improvement, the features are largely removed as shown in the right image in Figure Figure 7. We have produced a series of stacks using chopped SPO plates confirms this.

Another systematic defect, which became obvious with improved cleanliness of SPO plates, are drying stains at fixed positions on plates. These stains are small on plate level but become larger during stacking degrading the performance of the optics. The red circles in the left image in Figure 8 highlight the drying stains on plate one of a middle radius stack. These stacking defects are observed where plates come in contact with the support structures used during the SPO plates drying step, part of the cleaning process in the wet bench.

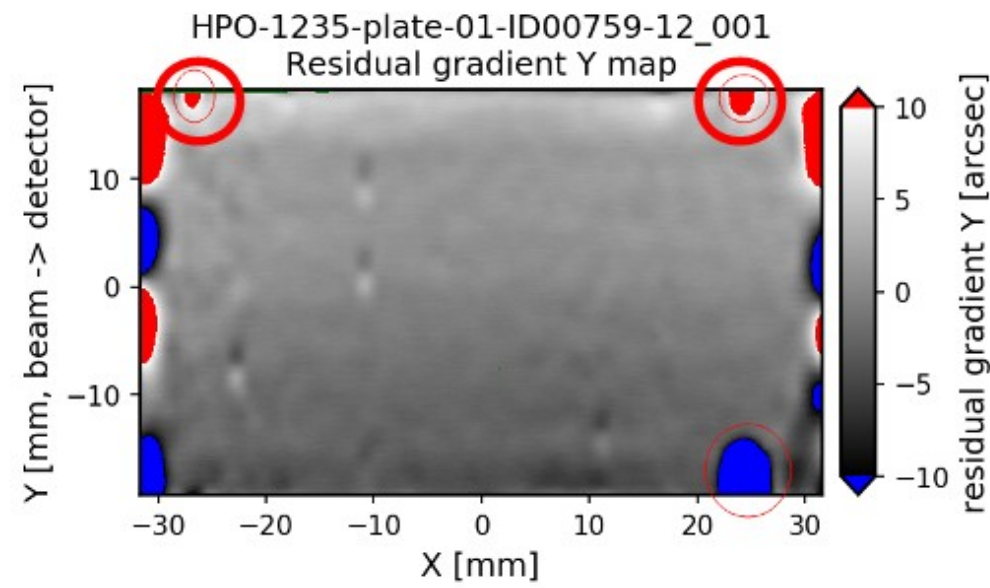

Figure 8. drying stains at the edge of a stacked middle radius SPO plate.

We were able to eliminate the drying stains by modifying the Marangoni drying parameters to minimize the quantity of water trapped at the interface between plates and their support rods and by re-designing the SPO plate process carriers. This is going to improve the quality of the central area, contributing to lower the HEW of the $70 \%$ contiguous area fraction.

The current wet bench has shown an excellent performance, however, as with any tool that runs continuously for long period of time, it has started to wear and parts are starting to break down. As SPO development is moving forward, we are in the process of procuring a new wet bench. This will guaranty the highest level of plate cleanliness with increased throughput compared to our current wet bench.

\section{CONCLUSIONS}

In this paper, we have summarized the current state-of-the-art in Silicon Pore Optics plate manufacturing technology. A customized dicing process is used to obtain ribbed square shaped SPO plates from $300 \mathrm{~mm}$ double-sided polished monocrystalline silicon wafers with normal and larger pores for increased effective area. Customized wedging equipment is used to fabricate SPO plates of the correct geometry, and industry-standard wet chemical processes to 
ensure bondable surfaces. In summary, a process flow has been developed to manufacture stackable SPO mirror plates with accurate control of the wedge angle, which is suitable to meet the requirements of Athena. With this combination of standard wafer processes and standard equipment, it will be possible to manufacture the required $\sim 150.000 \mathrm{SPO}$ plates for Athena in a cost-effective way within the time-scale of less than two years. We already produce more than 2.000 plates per year and are continuously ramping up production.

In view of further process improvements, TTV measuring capabilities have been added in terms of a TTV measurement system that has been developed to measure the SPO plates total thickness deviation more accurately. This helped to minimize wedge angle errors and entry and exits defects of the plates. In addition, systematic drying stains which lead up to a stack-up defect have been identified and eliminated and new wet bench is being procured for better cleanliness and larger throughput towards mass production of SPO plates.

\section{ACKNOWLEDGEMENTS}

We would like to thank all people for their excellent work on developing mirror plates for Silicon Pore Optics. We would also like to acknowledge the ESA, NWO (Athena, 184.034.002) and MPE funding making the development of Silicon Pore Optics possible.

\section{REFERENCES}

[1] Bavdaz, M. et al., "Progress at ESA on high-energy optics technologies", Proc. SPIE 5168, 136-147 (2004).

[2] Beijersbergen, M. et al., "Silicon pore optics: novel lightweight high-resolution X-ray optics developed for XEUS", Proc. SPIE 5488, 868-874 (2004).

[3] Kirpal, N. et al., "The Hot and Energetic Universe: A White Paper presenting the science theme motivating the Athena+ mission", arXiv e-prints arXiv:1306.2307 (2013).

[4] Wolter, H., "Spiegelsysteme streifenden Einfalls als abbildende Optiken für Röntgenstrahlen", Annalen der Physik, vol. 445, Issue 1, pp.94-114.

[5] Barret, D. et al., "The Athena X-ray Integral Field Unit (X-IFU)", Proc. SPIE 9905, id. 99052F 41 pp. (2016).

[6] Rau, A. et al., "The Hot and Energetic Universe: The Wide Field Imager (WFI) for Athena+", arXiv eprints arXiv:1308.6785.

[7] Wille, E., et al, "Silicon pore optics manufacturing plan and schedule for ATHENA", Proc. of SPIE Vol. 10699, 106993L (2018)

[8] Bavdaz, M. et al., "Optics developments for ATHENA", in [These Proceedings], Society of Photo-Optical Instrumentation Engineers (SPIE) Conference Series 11119-12 (Aug 2019).

[9] Ferreira, I. et al., "ATHENA: phase A study status and optics/instrument accommodation", in [These Proceedings], Society of Photo-Optical Instrumentation Engineers (SPIE) Conference Series 11119-27 (Aug 2019).

[10] Collon, M. J. et al., "Status of the silicon pore optics technology," in [These Proceedings], Society of PhotoOptical Instrumentation Engineers (SPIE) Conference Series 11119-20 (Aug 2019).

[11] Smith, R. K., "Arcus: the soft x-ray grating explorer", in [These Proceedings], Society of Photo-Optical Instrumentation Engineers (SPIE) Conference Series 11118-31 (Aug 2019).

[12] Keek, L. et al., "Stacking of mirrors for silicon pore optics", in [These Proceedings ], Society of Photo-Optical Instrumentation Engineers (SPIE) Conference Series 11119-OH (Aug 2019).

[13] Barrière, N. M. et al., "Assembly of confocal silicon pore optic mirror modules", in [These Proceedings], Society of Photo-Optical Instrumentation Engineers (SPIE) Conference Series 11119-18 (Aug 2019).

[14] Vacanti, G. et al., "Measuring Silicon Pore Optics", in [These Proceedings], Society of Photo-Optical Instrumentation Engineers (SPIE) Conference Series 11119-17 (Aug 2019).

[15] Girou, D. et al., "Environmental testing of silicon pore optics for Athena ", in [These Proceedings], Society of Photo-Optical Instrumentation Engineers (SPIE) Conference Series 11119-OK (Aug 2019).

[16] Massahi, S., et al, "Installation and commissioning of the silicon pore optics coatings facility for the Athena mission", in these proceedings of SPIE 11119-14 (2019). 
[17] Svendsen, S., et al, "Performance and stability of $\mathrm{Ir} / \mathrm{SiC}$ x-ray mirror coatings for ATHENA", in these proceedings of SPIE 11119-15 (2019).

[18] Barrière, N. M., et al, "Assembly of confocal silicon pore optic mirror modules", in these proceedings of SPIE 11119-18 (2019).

Proc. of SPIE Vol. 11119 111190E-8

Downloaded From: https://www.spiedigitallibrary.org/conference-proceedings-of-spie on 15 Dec 2019 Terms of Use: https://www.spiedigitallibrary.org/terms-of-use 